\title{
Investigation of Combustion Characteristics of Premixed Propane/Air Flame
}

\author{
Ali S. Al-Shahrani \\ College of Engineering, Jazan University, Jazan, KSA \\ Email: aalshahrany@jazanu.edu.sa
}

How to cite this paper: Al-Shahrani, A.S. (2019) Investigation of Combustion Characteristics of Premixed Propane/Air Flame. World Journal of Engineering and Technology, 7, 465-471. https://doi.org/10.4236/wjet.2019.73034

Received: May 22, 2019

Accepted: August 17, 2019

Published: August 20, 2019

Copyright ( 2019 by author(s) and Scientific Research Publishing Inc. This work is licensed under the Creative Commons Attribution International License (CC BY 4.0).

http://creativecommons.org/licenses/by/4.0/ (c) (i) Open Access

\begin{abstract}
The combustion process in hydrocarbon fuels, involves complicated chemical reactions associated with bond braking, radicals production and heat generation which are responsible for flames initiation. The conditions, such as pressure, temperature and mixture strength, make a strong influence on combustion. This paper reports an investigation of combustion characteristics of premixed propane/air flames and the effects of initial conditions on heat production rates, emissions (combustion products) and final equilibrium pressure and temperature values. Different mixtures concentrations were used in this study, including lean, stoichiometric and rich $(\phi=0.8,1.0,1.2)$, subject to different pressures and temperatures ranging from 5 - 40 bars and $350-600$ $\mathrm{K}$, respectively. The elevated pressures and temperatures values were deliberately selected in this study to have more data available in the literature to fill in the gap in research and also to cover conditions that are similar to those in engines, in an attempt to have a better understanding on how to control emissions from these engines which is a major concern nowadays. Results show that rich mixture of propane fuel produces the highest rate for carbon monoxide (CO) with slight increase as pressure and temperature increase, where the stoichiometric mixture produces the highest rate of carbon dioxide $\left(\mathrm{CO}_{2}\right)$. It was noted that this type of emission decreases with the increase of pressure and temperature. On the other hand, nitric acid (NO) was found to be the highest for the lean mixture with sharp increase as pressure and temperature increase. Finally, the combustion heat $(Q)$ is extracted from each mixture which plotted against pressure and it was also found that rich mixture of this fuel produces the highest and increases sharply with increased pressures and temperatures.
\end{abstract}

\section{Keywords}

Flames, Emissions, Combustion, Carbon Oxides, $\mathrm{NO}_{\mathrm{x}}$ 


\section{Introduction}

Atmospheric pollution has become a worldwide concern. This concern led to the consideration of investigating effects of combustion products of fossil fuels which produces a large amount of emissions to the atmosphere. It then became evident that the major species that would affect the ozone balance were the oxides of nitrogen $\mathrm{NO}_{\mathrm{x}}$ as well as carbon oxides $\left(\mathrm{CO}_{\mathrm{x}}\right)$ [1] [2]. One major source of such pollutants is automobile exhaust which uses fossil fuels (hydrocarbons) in their combustion systems to produce energy [3] [4]. So great interest remains in predicting and reducing these emissions, at elevated Temperatures $(T)$ and Pressures $(P)$.

So, understanding combustion process is an essential issue to control such emissions from industrial plants and engines as well. It is a fast exothermic gas-phase process and the initiated flame is a result of combustion reaction which can propagate sub sonically through combustion chamber. The motion of the flame relative to the unburned gas is the important feature. The reaction zone is usually called the flame front. This flame characteristic of spatial propagation is the result of the strong coupling between chemical reaction, the transport processes of mass diffusion and heat conduction, and fluid flow. The generation of heat and active species accelerate the chemical reaction. When these processes are in balance, a steady-state flame results [5]. The aim of combustion devices is to produce high temperatures for heat or power generation whilst producing the least pollutant emissions, under controllable conditions. Lean premixed combustion succeeds largely in the first count, whilst coming up short regarding the range of operable conditions. In internal combustion engines, lean combustion provides high efficiencies (due to the high specific heat ratio of air) and low emissions (due to low temperatures), but poor stability. In spark ignition engines, limits to stability can be overcome by injecting additional fuel in strategic locations near the spark plug, with penalties associated with the production of NOx and particulate matter. In gas turbines and other continuous flow devices, stability is often achieved by providing a richer pilot zone, again at the expense of higher emissions. In other cases, even though premixed conditions are the aim, limited time for evaporation and mixing creates nonuniformities short in fuel concentrations. In all of these situations, the final mixture will react under conditions where there is a range of equivalence ratios or mixture fractions over which the reaction will take place [6]. It then becomes an essential issue to conduct researches at an elevated conditions, which might help to understand the nature of such emissions, and more important the effective ways of minimizing its formation rates [7] [8]. This was done via using Computational Model (CM), at different high pressures and temperatures.

\section{Evaluating Emissions Concentrations from Burned Fuel}

The most important considerations when predicting $\mathrm{NO}_{\mathrm{x}}$ and $\mathrm{CO}_{\mathrm{x}}$ emissions for any hydrocarbon fuel are specifying the initial conditions for the combustion 
system which produces such emissions when burning used fuel. These conditions include pressures and temperatures initial values at each calculation run. Another way of evaluating such emissions is by calculating Emission Index, " $E P$ ' Which is defined as the ratio of mass of specifies " $\vec{i}$, to mass of burned fuel by the combustion processes [1]. This concept is demonstrated by applying Equation (1);

$$
E I_{i}=\frac{\dot{m}_{i}(\mathrm{~g} / \mathrm{s})}{\dot{m}_{f}(\mathrm{~kg} / \mathrm{s})}
$$

where,

$E I_{i}:$ Emission Index; $\dot{m}_{i}:$ mass of Emitted specie; $\dot{m}_{f}:$ mass of burned fuel.

For hydrocarbons fuel, " $E P$ ", can be determined from concentration mole fraction measurement of species of interest, together with those of all carbon atoms containing species.

$$
E I_{i}=\frac{X_{i}}{X \mathrm{CO}+X \mathrm{CO}_{2}} * \frac{x M W_{i}}{M W_{f}}
$$

where,

$M W_{f}$ : molecular weight of burned fuel; $M W_{i}$ : Molecular weight of emitted specie.

Term 1 in RHS of Equation (2) represents number of moles of specie, " $i$ " per mole of carbon atoms originated in the fuel, where Term 2 represents the conversion of Carbon moles to fuel moles.

In this work, CM method was applied. All thermodynamic processes had to be specified. The process was chosen to be "adiabatic temperature and composition at constant volume" which is identical to those in internal combustion engines [5] [8]. The chemical reactions approach which lead to formation of such emissions is beyond the scope of this work, more details can be found in [9] [10]. The mentioned model above, was capable to calculate all adiabatic temperatures and equilibrium compositions for flames at all pressures and temperatures. Three different mixture of propane-air with different equivalence ratios $(0.8,1.0,1.2)$ were proposed to study effects of fuel composition. The used model requires an input parameter in order to run the calculations. These parameters include initial temperature and pressure $\left(T_{u}, P_{u}\right)$, Equivalence ratio $\phi(0.8,1.0$ and 1.2), and the thermodynamic process at which these calculations will be run at which is mentioned above. An important parameter is Heat of Combustion extracted from the fuel, $Q(\mathrm{~kJ} / \mathrm{kg})$, in each run was also calculated for each mixture.

\section{Results and Discussion}

1) Three different air-fuel mixtures have been used for propane fuel $\left(\mathrm{C}_{3} \mathrm{H}_{8}\right)$, to evaluate the amount of emissions produced in mole fraction from combustion process for this fuel. First mixture was lean, $(\phi=0.8)$, second one was stoichiometry, $(\phi=1.0)$, and the third mixture was rich, $(\phi=1.2)$. Emissions species were, Nitrogen Oxide (NO), Carbon monoxide (CO) and Carbon dioxide $\left(\mathrm{CO}_{2}\right)$. Numerical calculated results were plotted in Figures 1-3, at different pressures and 
temperatures ranging from 5 - 40 bars and 350 - $600 \mathrm{~K}$, respectively.

2) Results showed that the highest values of $\mathrm{CO}$ emissions were produced from rich mixtures of propane-air flames $(\phi=1.2)$, where lean mixtures $(\phi=0.8)$ produced the least values of $\mathrm{CO}$ emissions. This is shown in Figure 1, for all pressures and temperatures.

3) On the other hand, $\mathrm{CO}_{2}$ emissions were noticed to be maximum values for stoichiometry $(\phi=1.0)$ mixtures and minimum values for rich mixtures $(\phi=$ 1.2). This is shown in Figure 2. Results also showed that $\mathrm{CO}_{2}$ values shortly increased

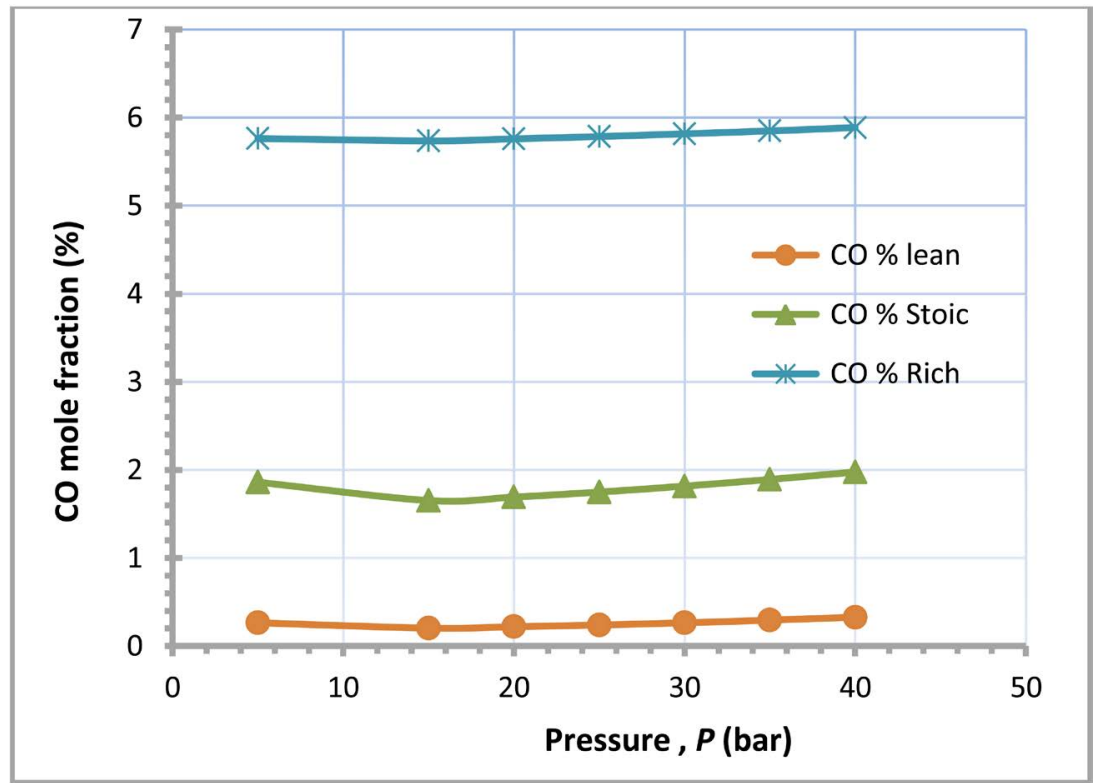

Figure 1. CO emissions mole fraction (\%) for propane mixtures $(\phi=0.8, \phi=1.0$ and $\phi=$ $1.2)$ at initial pressure and temperature, $P_{o}, T_{o}$ ranging $(5-40)$ bar and $(350-650) \mathrm{K}$.

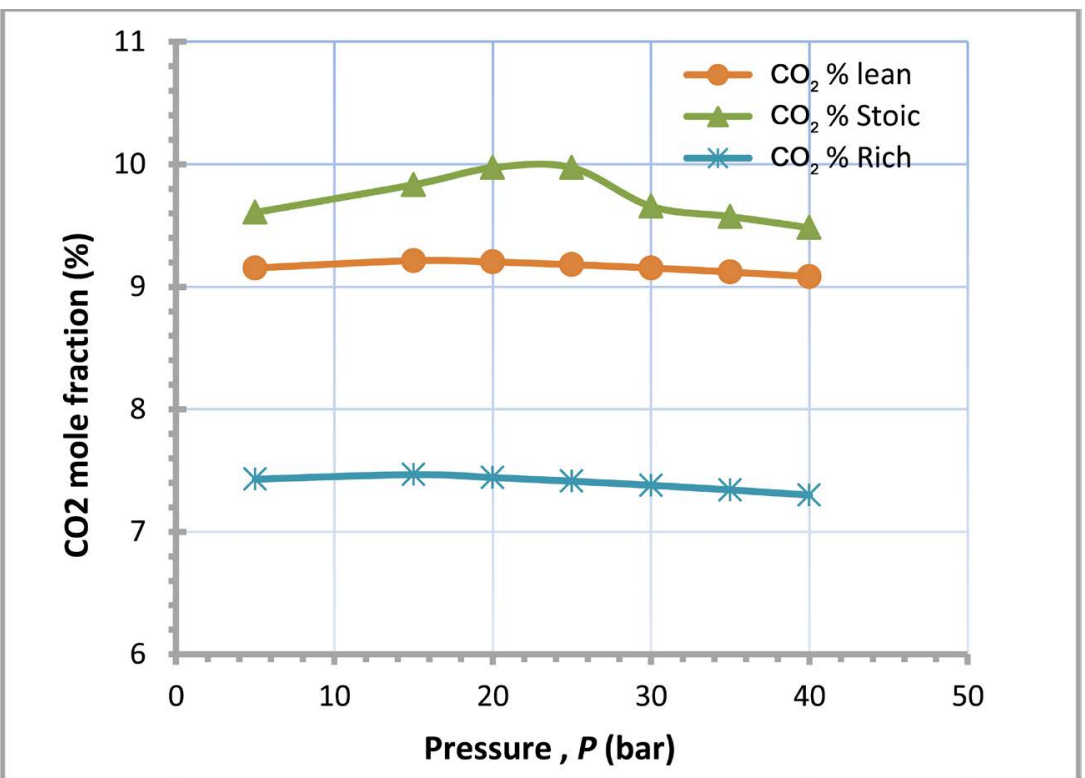

Figure 2. $\mathrm{CO}_{2}$ emissions mole fraction (\%) for propane mixtures $(\phi=0.8, \phi=1.0$ and $\phi=$ $1.2)$ at initial pressure and temperature, $P_{o}$, $T_{o}$ ranging $(5-40)$ bar and $(350-650) \mathrm{K}$. 
but then decreased as pressures and temperatures values increased for the stoichiometry $(\phi=1.0)$ mixtures.

4) Shown in Figure 3, NO emissions produced by propane-air flames. It was found that the highest values were for the lean mixtures $(\phi=0.8)$, and the least ones were for rich mixtures $(\phi=1.2)$. Results also showed that for all three mixtures, $\mathrm{NO}$ emissions increases with increased pressure and temperature.

5) Finally, heat of combustion, $Q(\mathrm{~kJ} / \mathrm{kg})$, was calculated for every mixture at all pressures and temperatures. The results were plotted in Figure 4. It was clear

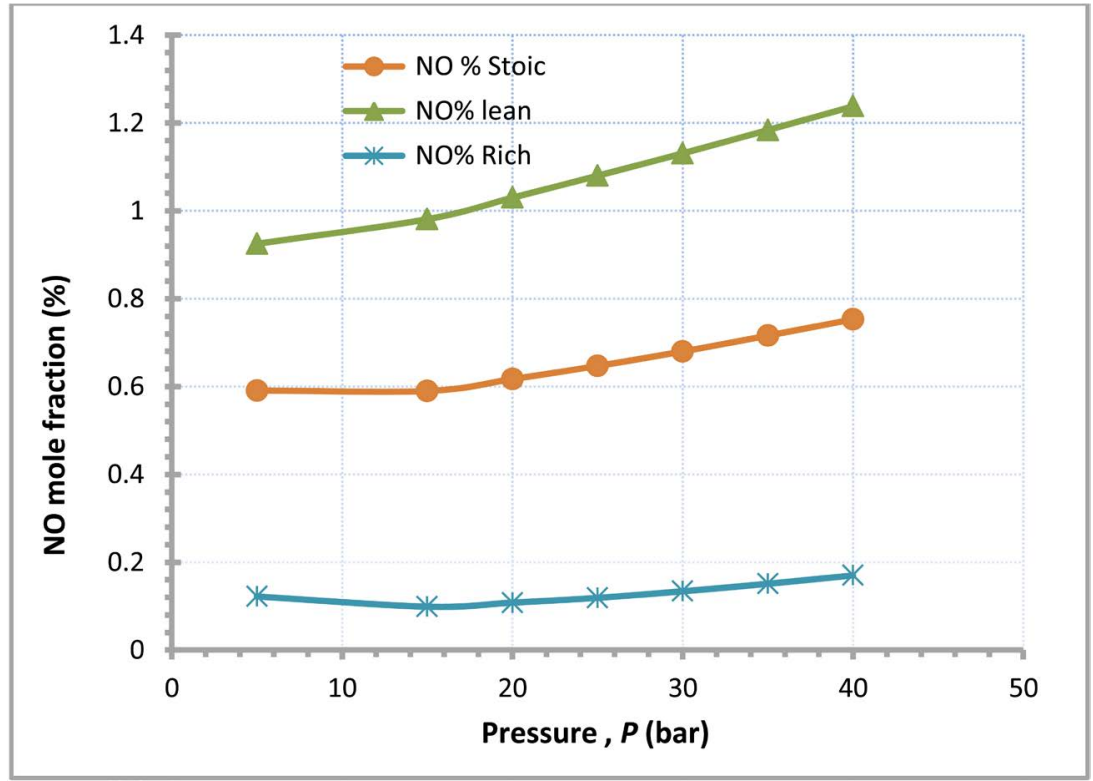

Figure 3. NO emissions mole fraction (\%) for propane mixtures $(\phi=0.8, \phi=1.0$ and $\phi=$ $1.2)$ at initial pressure and temperature, $P_{o}, T_{o}$ ranging $(5-40)$ bar and $(350-650) \mathrm{K}$.

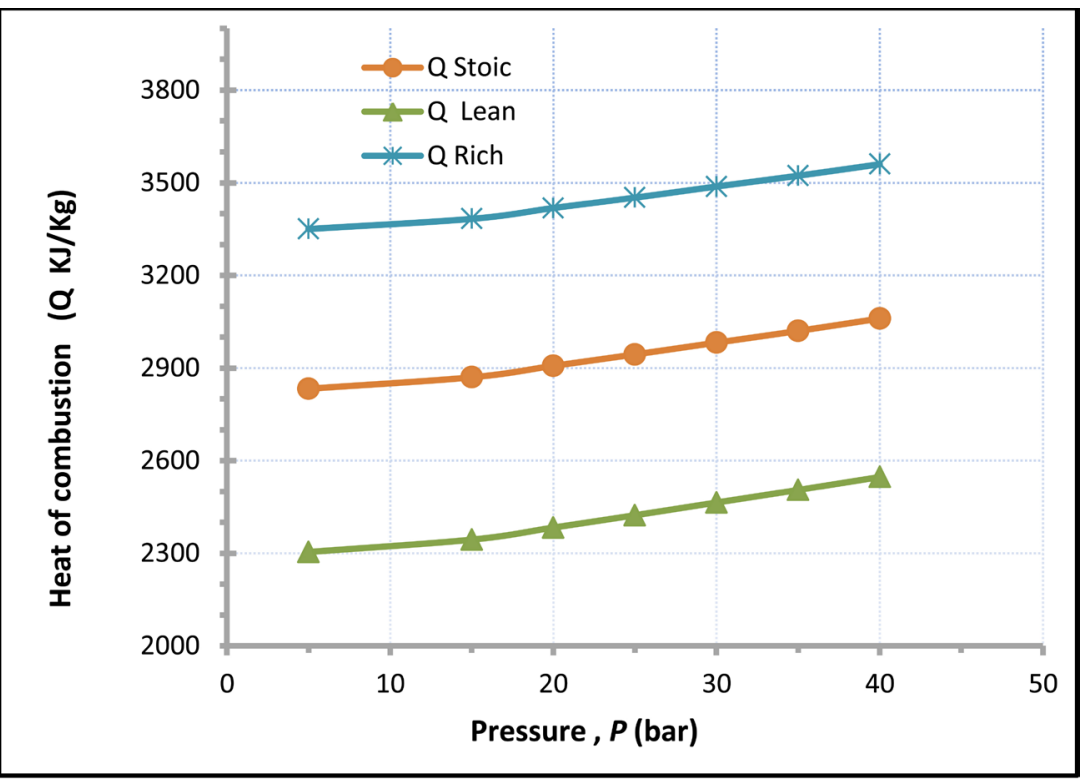

Figure 4. Heat of combustion, $Q$, for propane mixtures $(\phi=0.8, \phi=1.0$ and $\phi=1.2)$ at initial pressure and temperature, $P_{o}, T_{o}$ ranging $(5-40)$ bar and $(350-650) \mathrm{K}$. 
that rich mixtures of propane produced the highest values of combustion heat, $Q$, where minimum values was found to be for lean mixtures. Results also showed that fairly sharp increase in $Q$ values as pressure and temperature increase for all three mixtures.

\section{Conclusions}

In this paper, a computational model "CM" was used to evaluate emissions produced from propane fuel. These emissions include $\mathrm{CO}, \mathrm{CO}_{2}$, and $\mathrm{NO}$ for three different equivalence ratios: lean $(\phi=0.8)$, stoichiometry $(\phi=1.0)$, and rich $(\phi=$ 1.2) mixtures at different pressures and temperatures. It was quite evident from the outcomes of this study that concentrations of propane fuel $(\phi)$ for the three mixtures have strong influences on the amount of produced emissions at the end of each combustion process. It was also found that it has strong influences on the amount of combustion heat (Q), for each mixture.

Obtained results show that pressure increase has remarkable effects on NO formation rate, and very slight effects on $\mathrm{CO}_{\mathrm{x}}$ formation rates.

Propane fuel has good wide range of flammability limits. This is clear from the fact that when increasing temperatures, pressures, and mixture strength, there was no negative effect on ignition process.

This study showed that propane fuel produced decent values of combustion heat, $Q$, with gradual increase for all conditions without any sudden changes which is a strong indication for a stable combustion at all conditions even with high temperatures and pressures which normally causes instabilities in combustion process for other hydrocarbon fuels.

Finally, the current study may help in developing an optimum design of combustion devices to ensure good mixing and turbulence with high efficiency combustion also in selecting type of fuel in order to minimize pollutants emissions and avoid auto ignition and knocking which may damage combustion devices.

\section{Conflicts of Interest}

The author declares no conflicts of interest regarding the publication of this paper.

\section{References}

[1] Glassman, I. (1988) Combustion. Academic Press, Orlando.

[2] Abian, M., Peribanez, E., Millera, A., Bilbao, R. and Alzueta, M.A.U. (2013) Synergy between Nitrogen Oxides and Soot Precursors: Influence on Pollutants Emissions. Proceedings of the European Combustion Meeting, Lund, 2013.

[3] Heck, R. and Farrauto, R. (2001) Automobile Exhaust Catalysts. Applied Catalysis A: General, 221, 443-457. https://doi.org/10.1016/S0926-860X(01)00818-3

[4] Lox, E.S.J. (2008) Handbook of Heterogeneous Catalysis. Wiley-VCH Verlag GmbH \& Co., Weinheim.

[5] Heywood, J. (1988) Internal Combustion Engines Fundamentals. McGraw-Hill Book Company, New York. 
[6] Hochgreb, S. (2014) On Mixing and Shaking: Structure and Dynamics of Turbulent Stratified Flames. University of Cambridge, Cambridge.

[7] Galarbog, P.G., Alzuueta, M.U., Dam Johansen, K. and Miller, J.A. (1998) Kinetic Modeling of Hydrocarbon/Nitric Oxide Interactions in a Flow Reactor. Combustion and Flame, 115, 1-27. https://doi.org/10.1016/S0010-2180(97)00359-3

[8] Roy, M.M., Tomita, E., Kawahara, N., Harada, Y. and Sakane, A. (2009) Performance and Emission Comparison of a Supercharged Dual-Fuel Engine Fueled by Producer Gases with Varying Hydrogen Content. International Journal of Hydrogen Energy, 34, 7811-7822. https://doi.org/10.1016/j.ijhydene.2009.07.056

[9] Papagiannakis, R.G., Rakopoulos, C.D. and Hountaalas, D.T. (2010) Emission Characteristics of High Speed, Dual Fuel, Compression Ignition Engine Operating in a Wide Range of Natural Gas/Diesel Fuel Proportions. Fuel, 89, 1397-1406. https://doi.org/10.1016/j.fuel.2009.11.001

[10] Griffith, D.W.T., Bryant, G.R., Hsu, D. and Reisinger, A.R. (2008) Methane Emissions from Free-Ranging Cattle: Comparison of Tracer and Integrated Horizontal Flux Techniques. Journal of Environmental Quality, 37, 582-591.

https://doi.org/10.2134/jeq2006.0426 